\title{
Food Handlers Understanding about Health Aspects at Eatery Premises in the State of Kedah: Pre and Post Training Programme for Food Handlers (LPM)
}

\author{
Noor Azniza Ishak ${ }^{1}$, Jamaludin Mustaffa ${ }^{2}$, Kamal Ab Hamid ${ }^{3}$, Azemi Shaari ${ }^{1}$, Mohd Hilmi Hamzah ${ }^{4} \&$ Mohd \\ Khairuddin Mohd Talib ${ }^{5}$ \\ ${ }^{1}$ Department of Counseling, School of Social Development, College of Arts and Sciences, Northern University \\ of Malaysia (UUM), Kedah, Malaysia \\ ${ }^{2}$ Department of Social Work, School of Social Development, College of Arts and Sciences, Northern University \\ of Malaysia (UUM), Kedah, Malaysia \\ ${ }^{3}$ School of Technology and Operations Management, College of Business, Northern University of Malaysia \\ (UUM), Kedah, Malaysia \\ ${ }^{4}$ Centre for Policy Research and International Studies (cenPRIS), Universiti of Science Malaysia (USM), Penang, \\ Malaysia \\ ${ }^{5}$ Department of Health Kedah, Ministry of Health Malaysia, Malaysia \\ Correspondence: Mohd Hilmi Hamzah, Centre for Policy Research and International Studies (cenPRIS), \\ Universiti of Science Malaysia (USM), Penang, Malaysia. E-mail: h_mamat@yahoo.com
}

Received: March 11, 2013 Accepted: May 21, 2013 Online Published: June 28, 2013

doi:10.5539/ass.v9n9p74

URL: http://dx.doi.org/10.5539/ass.v9n9p74

\begin{abstract}
This article will discuss the differences before and after food handlers attending a course to understand the safety and hygiene of their eatery premises by looking at three aspects; i.e. food hygiene, personal hygiene and eatery premises hygiene. This is a fieldwork observation research using a survey method (questionnaire) conducted on a population of food handlers who attended a course organised by SLPM. The overall population consists of approximately 8000 food operators who were undergoing trainings for food handlers throughout the state of Kedah. The number of respondent who answered the questionnaires at the pre-programme and post-programme was 400 food handlers who were at that time undergoing food handlers' trainings at schools appointed by LPM specially chosen as the sample of this study. The researchers focused only on the setting of the study which are all the way through the entire state of Kedah looking at the districts of Kulim, Kuala Muda, Kota Setar, Alor Setar and Langkawi. The analysis on the level of understanding about health among food handlers revealed that overall, food handlers responded that they really understand the importance of health in order to administer their business. The result about the overall understanding about health, indicating that before underwent the training, the level of understanding about overall health among the food providers was already high, indicating that they understand that health. Overall, the understanding of the importance of health in the running of business premises indicates a high level. In comparing the understanding level of pre-programme and post-programme, the study reveals that food handlers have already understood the importance of keeping their food, self and premises hygienic while running their business even before they underwent the course module, and their level of understanding increased after attending the course. However, the ministry should always stay alert and sensitive so as this would continue. Leaving this issue unattended will only cause a loss to the food handlers' business because the understanding of food, personal and premise hygiene is very much vital because it is the pull factor that attract customers to go to their premises of which in the end will prosper their business.
\end{abstract}

Keywords: health aspects, programme for food handlers (LPM)

\section{Introduction}

Food handlers are individuals who have direct involvement in food handling processes, from the preparation to the ready-to-sell food. They include hawkers, restaurant workers, cooks, food factory workers and many more. Although each and every person is equipped with experience, their education background and food handling 
practices are different making it difficult to determine the level of safety and cleanliness of their product. Hence, a comprehensive training programme must be provided to all food handlers to ensure that they possess enough and relevant knowledge about food handlings.

Sekolah Latihan Pengendali Makanan (SPLM) or Food Handlers Training School is an organization that is approved by the Ministry of Health Malaysia, established to provide basic training on cleanliness for food handlers. Its establishment is in line with the government's effort to overcome problems related to overall food safety via education on food safety towards ensuring that customers' health are assured. The main objective of the establishment of SPLM is to provide educational facilities to food handlers in opening up their consciousness, providing knowledge and skills on food safety and cleanliness. The LPM Programme, as approved by the Ministry of Health, Malaysia, has started to play its role since1996. The ministry had signed an MOU with UKM via Food Safety and Cleanliness Training Academy on March 2, 2006. Since then, ALKEM has taken over the Food Safety and Quality by training qualified trainers. ALKEM is also responsible in the SLPM registration process, supervising and reviewing SLPM curriculum from time to time.

Through various training programmes organised by SLPM, food handlers have been exposed to basic knowledge on the cleanliness aspect and food safety, as well as identify food that are not safe to be consumed. It is also hoped that food handlers could practise the right food handling procedures at their very premises in order to strengthen the effectiveness of this programme; the State Health Department has always observed and supervised its syllabus from time to time. Among the objectives for the implementation of the LPM Programmes are Making sure that all food handlers undergo the LPM course once in a lifetime Providing consciousness about food cleanliness aspects on self and premises among food handlers Ensuring that food poisoning cases in Malaysia, especially in the state of Kedah, decrease Accomplishing the governments mission to ensure that 100\% food handlers in Malaysia are trained by 2012 Enhancing knowledge on attitude and practices (based on need) by conducting extra training Producing food providers who are knowledgeable in hygiene practices and law requirement.

In 2009, 11 SPLM registered in Malaysia had organised trainings for food handlers in the state of Kedah. SPLM had trained 2005 food handlers throughout the state. 60 sessions had been planned, but only 24 sessions were audited by the Kedah State Department. 2012 had shown 13 registered SPLM and 168 training sessions were organised to 5058 food providers.

Food handlers are required to attend food handling training program modules and one set of rules to be abided by supervisors or the food handlers based on the General Principles of Food Hygiene standard. The General Principles of Food Hygiene is a comprehensive guidance for the preparation of food that are safe to be consumed. Among the aspects included in the standard principles is the cleanliness of the food preparation premises, physical cleanliness; i.e. free from bushes that promotes the breeding of animals or vermin such as the rodent. The internal cleanliness, includes no broken or cracked tiles or marbles, has separate storage for raw coking materials as well as readily prepared food. Fruits and vegetables must be kept separately from raw materials such as meat, egg and poultry. The other aspect is hygiene awareness among the workers. Cleanliness among the workers include covering their head by wearing a cap, wearing apron and keeping their nails short without wearing any rings on their fingers (Ministry of Education and Ministry of Health, Malaysia, 1989).

Conversely, there are still food handlers who fail to practice the standard procedures and principles of food hygiene in their eatery premises. This is in accordance with the statement by Md Zan (2008), who stated that awareness of proper food handling preparation such as hygiene among food handlers are still at a low level despite the various training courses offered and made available for them, some did not put this into practices.

Various questions can be presented or asked to costumers so as to know whether the mentioned problem really happen as well as to identify and determine if the customers know about the ethics and principled rule out to be abided by the food operators. Thus, this article will discuss the differences before and after food handlers attending a course to understand the safety and hygiene of their eatery premises by looking at three aspects; i.e. food hygiene, personal hygiene and eatery premises hygiene.

\section{Understanding the Concept of Heath}

According to Kamus Dewan (2004), understanding means understand with knowledge in mind about something. This includes the ability to translate ideas from one from to another, interpret ideas and effects and consequences (Lamberg \& Lamb, 1980). Some scholars divide understanding into three stages-literal, interpretation and critical and creative. Literal understanding refers to the ability to understand at the surface. Interpretation, on the other hand is the ability to explain and critical and creative refers to the ability to evaluate, make judgement of something (information, idea, opinion etc.) 
The aspect of understanding in cleanliness and hygiene is vital to health especially to food handlers managing eatery premises. When discussing about the understanding about health aspect, the Division of Food Safety and Quality, Ministry of Health Malaysia (2001) has ruled out three main aspects of safe and quality food -- food hygiene, personal hygiene and eatery premises hygiene. For the purpose of this research, food handlers will be enquired about their understanding about health to determine as to what extend do they understand the importance of understanding health while managing a business, pre and post training.

\section{Literature Review: Understanding Health}

A survey by Mazilah (2008) identifies the food handlers' understanding of hygiene and safety practices at Taman Seri Pulai, Johor Bahru. The findings reveals that food handles felt that they understand that hygiene and safety procedures must be practices while handling food.

The findings of a study by Mohd Rizal and Noor Aini (2020) about understanding related to personal hygiene habits, premises hygiene and food preparation sections as well as safety and the cleanliness of cooking and serving tools by school canteen operators in Skudai Zone, Johor Bahru indicated that the level of knowledge about food hygiene practices among canteen operators is high. This is evident as canteen operators did perform the requested standard food hygiene practices when handling food.

Another study by Jones and Weimer (1977), in the United States, indicated that $75 \%$ of households used to experience sickness caused by unsafe, damage and expired food. They realised that this is due to the low practices in handling safe and hygienic food.

\section{Methodology}

This is a fieldwork observation research using a survey method (questionnaire) conducted on a population of food handlers who attended a course organised by SLPM. The pre-programme and post-programme design is used in collecting data. The pre-programme data was collected at the initial stage of the course while the post-programme data collection was made at the end of two months after the programme was over. The overall population consists of approximately 8000 food operators who were undergoing trainings for food handlers throughout the state of Kedah. The number of respondent who answered the questionnaires at the pre-programme and post-programme was 400 food handlers who were at that time undergoing food handlers' trainings at schools appointed by LPM specially chosen as the sample of this study. The researchers focused only on the setting of the study which are all the way through the entire state of Kedah looking at the districts of Kulim, Kuala Muda, Kota Setar, Alor Setar and Langkawi. The instruments used in this study include the understanding about health aspects which are then divided into three dimensions-food hygiene, personal hygiene and eatery premise hygiene based on the food handlers' training module as well as previous studies specially modified to cater to the need of the study. Data were analysed using the SPSS 16.0 software, looking at descriptive statistical analysis in order to look at the frequencies and percentage which were presented in a graphic form.

\section{Findings}

\subsection{Level of Understanding about Overall Health}

The analysis on the level of understanding about health among food handlers revealed that overall, food handlers responded that they really understand the importance of health in order to administer their business. This is proven in the finding of analysis which showed a frequency and percentage of 89.8 percents or 359 food handles who demonstrate a high level of the overall understanding of health. Please refer Table 1.

Table 1. Frequencies and percentages of the health understanding level $(n=400)$

\begin{tabular}{ccc}
\hline Health Understanding & Frequency & \% \\
\hline Low & 1 & 0.2 \\
Moderately & 40 & 10.0 \\
High & 359 & 89.8 \\
\hline
\end{tabular}

\subsection{Level of Understanding about Health in the Aspect of Food Hygiene Dimension}

The finding on the level of understandings about food hygiene in this study indicates that while managing their businesses, the majority of food handlers state that they possess a high level of understanding as they really 
understand the importance of food hygiene in order to attract customers to go to their premises because customers are really concern about the taste of food that should be delicious the business premises that should be clean and hygienic. This is proven by the frequency and percentage of this dimension which indicated that 89.3 percent or 337 food handlers showed a high level of understanding. Please refer Table 2.

Table 2. Frequency and percentage of the understanding level about food hygiene dimension $(n=400)$

\begin{tabular}{ccc}
\hline Food Hygiene & Frequency & $\%$ \\
\hline Low & 2 & 0.5 \\
Moderately & 41 & 10.2 \\
High & 377 & 89.3 \\
\hline
\end{tabular}

\subsection{Dimension of Level of Understanding about Health in the Aspect of Personal Hygiene}

The finding on the level of understandings about personal hygiene dimension indicates a high level in which respondents understand that personal hygiene is vital in ensuring the health of their customers and themselves is always good in which 88 or frequencies of respondents states that is 352 as shown in Table 3 .

Table 3. Frequency and percentage of the level of understanding about personal hygiene dimension $(n=400)$

\begin{tabular}{ccc}
\hline Personal Hygiene & Frequency & $\%$ \\
\hline Low & 4 & 1.0 \\
Moderately & 44 & 11.0 \\
High & 352 & 88.0 \\
\hline
\end{tabular}

\subsection{Dimension of Level of Understanding about Health in the Aspect of Business Premises}

Similarly, the level of understanding about health in the aspect of business premises indicated that the respondents understand that the surrounding of their business premises is important in attracting customers to come to their premises. This is proven by the 85 percent or 340 respondents who stated likewise. Please refer Table 4 .

Table 4. Frequency and percentage of level of understanding about food premises dimension $(n=400)$

\begin{tabular}{ccc}
\hline Business Premises & Frequency & $\%$ \\
\hline Low & 4 & 1.0 \\
Moderately & 56 & 14.0 \\
High & 340 & 85.0 \\
\hline
\end{tabular}

\subsection{Comparison of the Understanding about Overall Health before and after the Training}

The result about the overall understanding about health is transated by Table 5, indicating that before underwent the training, the level of understanding about overall health among the food providers was already high, indicating that they understand that health is a vital aspect in running a business with 91.0 percent or 364 respondents share the opinion. However, afer the training, the level of their understanding showed a slight decrease with 90.0 percent or 360 respondents said so.

Table 5. Comparison of frequency and percentage of understanding about health $(n=400)$

\begin{tabular}{ccccc}
\hline \multirow{2}{*}{ Health Understanding } & Before & \multicolumn{2}{c}{ After } \\
& Frequency & \% & Frequency & \% \\
\hline Low & 2 & 0.5 & 2 & 0.5 \\
Moderately & 67 & 16.8 & 45 & 11.2 \\
High & 331 & 82.7 & 353 & 88.3 \\
\hline
\end{tabular}


5.6 Comparison of Understanding about Health in the Aspect of Food Hygiene before and after Attending the Training

The study about the understanding of food hygiene in Table 6 pointed out that before attending the training, food providers had demonstrated a high level of understanding. They understand that food hygiene is a very important factor in running their business with 91.0 percent or 364 respondents indicated the respond. However, the value showed a slight decrease with 90.0 percent of the respondent or 360 of them denoted the answer.

Table 6. Frequency and percentage of understanding about food hygiene dimension $(\mathrm{n}=400)$

\begin{tabular}{ccccc}
\hline \multirow{2}{*}{ Food Hygiene } & \multicolumn{2}{c}{ Before } & \multicolumn{2}{c}{ After } \\
& Frequency & $\mathbf{\%}$ & Frequency & \% \\
\hline Low & 3 & 0.8 & 6 & 1.5 \\
Moderately & 33 & 8.2 & 34 & 8.5 \\
High & 364 & 91.0 & 360 & 90.0 \\
\hline
\end{tabular}

5.7 Comparison of Understanding about Health in the Aspect of Personal Hygiene before and after Attending the Training

As for personal hygiene, Table 7 explained that the level of understanding about personal hygiene among food handlers are high which demonstrated that they understand the importance of food hygiene for their business. This is supported by 85.0 percent or 340 of the respondents. Nevertheless, after underwent the training module, the number of rspondents who saw in importance of personal hygiene increased to 90.8 percent or 363 respondents.

Table 7. Frequency and percentage of the comparison about personal hygiene dimension $(\mathrm{n}=400)$

\begin{tabular}{ccccc}
\hline \multirow{2}{*}{ Personal Hygiene } & \multicolumn{2}{c}{ Before } & \multicolumn{2}{c}{ After } \\
& Frequency & $\mathbf{\%}$ & Frequency & \% \\
\hline Low & 5 & 1.2 & 6 & 1.5 \\
Moderately & 55 & 13.8 & 31 & 7.8 \\
High & 340 & 85.0 & 363 & 90.8 \\
\hline
\end{tabular}

5.8 Comparison of the Understanding about Health in the Aspect of Business Premises before and after Attending

Based on the analysis of the cleanliness of the eatery business premises, Table 8 indicated that the respondents possessed a high level of understanding showing that the food providers understand the importance of keeping their premises clean for their business as translated by 84.8 percent or 339 respondents. The level of understanding increased to 89.0 percent or 356 respondents after the training.

Table 8. Frequency and percentage of the comparison of the understanding about the cleanliness of business premises dimension $(n=400)$

\begin{tabular}{ccccc}
\hline \multirow{2}{*}{ Health Understanding } & \multicolumn{2}{c}{ Before } & \multicolumn{2}{c}{ After } \\
& Frequency & $\mathbf{\%}$ & Frequency & \% \\
\hline Low & 8 & 2.0 & 4 & 1.0 \\
Moderately & 53 & 13.2 & 40 & 10.0 \\
High & 339 & 84.8 & 356 & 89.0 \\
\hline
\end{tabular}

\section{Discussion}

Overall, the understanding of the importance of health in the running of business premises indicates a high level. Similarly, the dimensions of understanding of food hygiene, personal hygiene and cleanliness of food premises operators show a high level too. Therefore, it can safely be concluded that the course modules have shown that 
food handlers understand that food hygiene, personal hygiene and business premises hygeine are important factors to develop their business premises.

In comparing the understanding level of pre-programme and post-programme, the study reveals that food handlers have already undestood the importance of keeping their food, self and premises hygeinic while running their business even before they underwent the course module, and their level of understanding increased after attending the course. Similarly, the dimensions of food hygiene, personal hygiene and cleanliness of premises had shown that they have already understood the signinicants of the three dimensions to their business even before the training programme and it increases after the training.

\section{Conclusion}

In a nutshell, 400 respondents among the food handlers from various districts in the state of Kedah had taken part in this study. The finding reveals that the level of understanding of the three dimensions of food, personal and eatery premises hygeine are at the high level.

However, the ministry should always stay alert and sensitive so as this would continue. Leaving this issue unattended will only cause a loss to the food handlers' business because the understanding of food, personal and premise hygeine is very much vital because it is the pull factor that attract customers to go to their premises of which in the end will prosper their business.

\section{References}

Aiken, L. R. (1980). Attitude measurement and research. In D. A. Payne (Ed.), Recent developments in affective measurement (pp. 1-24). San Francisco, CA.: Jossey Bass.

Miscel, W. (1971). Introduction to personality. New York: Holt, Rinehart and Winston Inc.

Robert, J. E. (2002). Family rituals and deviant behavior. PhD Thesis. Univesity of North Texas.

Sofiah, Z. (2003). The level of individual self-concept among secondary boarding school. Retrieved from http://www.moe.gov.my

Stufflebeam, D. L., \& Webster, W. J. (1980). An analysis of alternative approaches to education. Educational Evaluation and Policy Analysis, 2, 5-20.

Tsytsarev, S., Manger, J., \& Lodrini, D. (2000). He use of the reinforcement and punishment on incarcerated and probated substance-abusing juvenile offenders. International Journal of Offender therapy and Comparative Criminology, 44, 1. http://dx.doi.org/10.1177/0306624X00441003

\section{Copyrights}

Copyright for this article is retained by the author(s), with first publication rights granted to the journal.

This is an open-access article distributed under the terms and conditions of the Creative Commons Attribution license (http://creativecommons.org/licenses/by/3.0/). 